Oceanography. British ships have observed directly the deep ocean currents of the North Atlantic using the 'Swallow' acoustic signalling float which can be set to drift at the required depth. One of the currents measured was a southward one below the Gulf Stream.

Nuclear radiation. The existence of the International Geophysical Year network of nuclear sampling stations in Europe permitted a detailed study to be made of the diffusion of radioactive material released by the Windscale nuclear reactor accident in November 1957.

The full prescribed observational work ceased with 1958 and the main task of the present and future is the study of the observations made during the year. It is, however, planned to continue some observations, apart from those which are part of regular meteorological, etc., services, during 1959 under the title "International Geophysical Co-operation 1959".

The International Council of Sciontific Unions has formed special committees to co-ordinate further international work in antarctic research, oceanic research and space research.

A further possibility is the making of a magnetic survey on a world-wide scale during the next sunspot minimum for comparison with the magnetic observations made during the maximum period with which the International Geophysical Year was timed to coincide.

\title{
RADIO FIELD-STRENGTHS IN THE TROPICS
}

$\mathbf{I}^{\mathrm{T}}$ $T$ is well known that radio-communications conducted by waves which are propagated by reflexion from the ionosphere are critically dependent on the properties of the layers of ionized gas which transmit and attenuate the signals. The regular observation of the characteristics of the ionosphere at stations distributed widely over the Earth's surface has made it possible to understand and explain many phenomena which were obscure even ten years ago. The International Radio Consultative Committee has, among its other studies, been investigating many technical problems involving the propagation of radio-waves by way of the ionosphere; and of these a most important one is that of tropical broadcasting, for which high-frequency waves are much more effective than medium waves on account of the very high atmospheric noise-level present in most tropical regions. Unfortunately the attenuation of the signals in the higher-frequency bands is much greater during the day than is usual at higher latitudes and the reflecting layers are also less stable. Thus the problem of providing an adequate signal-tonoise ratio is considerably more difficult in the tropics.

The past studies of the International Radio Consultative Committee had shown that the standard methods of computing the field-strength of sky-wave signals wore considerably in error at low latitudes; but it also became clear that the additional basic data obtained in recent years provided an explanation of many of the discrepancies disclosed. In a report* by W. R. Piggott, recently published by the Department of Scientific and Industrial Research, Radio Research Station, this subject is reviewed with the aid of an analysis of the problem of identifying the most effective type of ionospheric reflexion for particular circumstances. This report shows that some of the difficulties in interpreting the results of field-strength measurements at low latitudes have been due to changes in the dominant mode of ionospheric propagation, and the consequent variations in the attenuation of the waves, and the angle of elevation at which they arrive at the receiver. The rate of advance of knowlodge of this subject depends on the continual interplay of practical observations with theory; and it is hoped that the publication of this roport, together with its presentation at the Plenary Assembly of the International Radio Consultative Committee recently held in Los Angeles, will encourage radio research workers in low latitudes to investigate their wave-propagation phenomena in more detail.

* Department of Scientific and Industrial Research. Radio Research. Special Report No. 27; The Calculation of the Median Sky Wave Field Strength in Tropical Regions. By W. R. Piggott. Pp. 38. (London : H.M. Stationery Office, 1959.) 2s. $6 \bar{d}$. net.

\section{BRITISH BOOKS AND FOREIGN MARKETS}

T reply to a series of questions in the House of Commons on June 22 regarding the supply of British books and periodicals overseas, Dr. C. Hill, the Chancellor of the Duchy of Lancaster, made a long statement which was circulated in Hansard. The study of ways and means of increasing the flow of British books and periodicals overseas has now been completed. Recognizing that British books can do much to help other peoples to understand our way of life and that they make a very real contribution to the life and thought of other nations, the statement points out that there is an ever-increasing demand for reading-matter in English, and we must do more to promote the flow of British reading-matter overseas. Other countries are already producing large amountis of well-produced attractive literature which is easy to read and inexpensive and is aimod particularly at Asian and African countries. Although in 1958 exports totalled nearly $£ 24$ million, or almost two-fifths of the turnover of the United Kingdom book trade, several countries impose, for eurrency reasons, substantial restrictions on imports of British books and periodicals and our exporters cannot make further headway in these markets. Low individual incomes in many countries and the lack of effective library and other distribution systems are also major difficulties.

Accordingly, the Government has decided to take five steps to promote the export of British books and periodicals :

(i) To enter into negotiations with various countries with the aim of establishing schemes operating 